\title{
Implementation of Spiraled Planar Inverted-F Antenna for Multiband Applications
}

\author{
T.Shanmuganantham, PhD. \\ Assistant Professor \\ Department of Electronics Engineering \\ Pondicherry University, Puducherry, India-605014
}

\author{
G.Rajender \\ M.Tech. Electronics \\ Department of Electronics Engineering \\ Pondicherry University, Puducherry, India-605014
}

\begin{abstract}
A spiraled planar inverted-F Antenna (PIFA) for Multiband frequencies of $2.65 \mathrm{GHz}, 4.10 \mathrm{GHz}$ and $5.85 \mathrm{GHz}$ for wireless local area network (WLAN) applications proposed in this paper. Simulation tool based on the method of moments (IE3D) has been used to analyse and optimize the antenna. The proposed antenna possesses the properties of good performance, compact size (about $50 \%$ of a typical PIFA), low profile, and low cost. Hence, it is suitable for combo WLAN system.
\end{abstract}

\section{Keywords}

Multiband antennas, Planar Inverted-F Antenna (PIFA), Spiraled PIFA.

\section{INTRODUCTION}

Current trends in science and technology make the communication in ease and rapid with the employment of wireless communication standards. Since 1999, the WLAN standards including IEEE $802.11 \mathrm{a} / \mathrm{b} / \mathrm{g}$ systems were established by IEEE 802.11 Group [1]. In U.S., the $802.11 \mathrm{~b} / \mathrm{g}$ WLAN standards are used for the frequency range from 2.45 to 2.65 $\mathrm{GHz}$ as the 802.11a standards are used from 5.15 to $5.5 \mathrm{GHz}$ (indoor) and 5.125 to $5.85 \mathrm{GHz}$ (outdoor)[5]. In the real-world applications, the $802.11 \mathrm{~b}$ system was first implemented utilizing the direct-sequence spread spectrum (DSSS) modulation scheme with the data rate up to $11 \mathrm{Mbps}$, yet the $802.11 \mathrm{~g}$ system for higher transmission data rate (up to $54 \mathrm{Mbps}$ ) was done later through the same frequency band as the $802.11 \mathrm{~b}$ but with orthogonal frequency division multiplexing (OFDM) modulation scheme[1-2]. Since antenna is the prime component of the wireless network system and moreover its compactness attracted the research persons more and more enthusiastic towards developing lots of wireless systems. Various antennas designed on the printed circuit board (PCB) have been proposed for $802.11 \mathrm{~b} / \mathrm{g}$ systems with $2.65 \mathrm{GHz}$ band, e.g., the hook-like radiation strip [1] and the inverted-F antennas [2]-[4].To enhance the communication capability of a unit cell, a combo system with $802.11 \mathrm{a} / \mathrm{g}$ or $802.11 \mathrm{a} / \mathrm{b} / \mathrm{g}$ standards is currently developed. In this combo system, the antennas are like transceivers operating in $2.65,4.1$ and $5.85 \mathrm{GHz}$ frequency bands but the space allocated for the antennas is usually quite limited, particularly for those at the client terminal (PCMCIA or USB interface). In order to reduce the antenna size, a Multiband antenna with a single input port is needed. This antenna should not only have good input impedance match but also offer proper antenna gains (with peak gain larger than $0 \mathrm{dBi}$ ) and radiation patterns as Omnidirectional as possible for both $2.65 \mathrm{GHz}$, $4.10 \mathrm{GHz}$ and $5.85 \mathrm{GHz}$ bands to at least satisfy the Multiband indoor application. Certain design use two similar resonators to achieve Multiband operations, such as double inverted-F antenna, triple U shaped monopole, F-shape monopole, open loop coupled monopole, monopole with parasitic plane [13], and double-T monopole. And some of these designs use a single block antenna with multiple resonant modes to achieve Multiband operations, such as tapered bent folded monopole, meandered CPW-fed monopole F-shaped monopole, G-shaped monopole T-shaped monopole with sleeves and flat plate antenna with shorted element[5-8]. The planar inverted-F antenna (PIFA) is widely used because of several advantages such as easy to fabricate, input impedance compatibility with no outer circuit, having omnidirectional pattern, etc. However, its length is limited to be a quarter wavelength of the operating frequency, which usually occupies quite a few amount of space in PCB. Besides, the single inverted-F antenna can only be operated at the certain resonant frequency, which is unable to supply the market needs of Multiband applications. A solution to this, we propose a spiraled PIFA antenna structures by means of spiraling an inverted-F antenna [as Fig. 1] which achieves Multiband operation which in turn operates at 2.65, 4.10 and $5.85 \mathrm{GHz}$ frequency bands. Both the antennas are simulated on the FR4 substrate with $0.8 \mathrm{~mm}$ thickness for our research work. The operating parameters such as return loss, Antenna Efficiency, directivity, Gain and radiation patterns at various frequencies, of the proposed antenna is presented in the following Section.

\section{PROPOSED ANTENNA STRUCTURE}

The proposed spiraled PIFA antenna structure is shown in Fig.1. The spiral inductor loaded on the antenna can be realized both Multiband operation and miniaturizes the size of the conventional inverted-F antenna. The chosen ground width is 46 mm compatible for PCMCIA interface. The antenna placed near the edge of ground plane is possible mainly for antenna diversity. In this section, the effect of the spiraled PIFA is discussed.

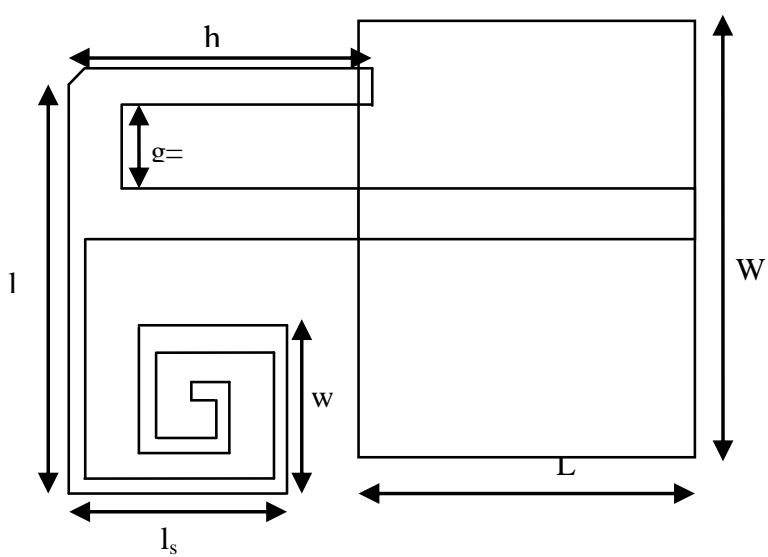

Fig1: Proposed spiraled PIFA Antenna

In the proposed spiraled PIFA Antenna structure, the Microstrip feed line is connected to a horizontal metal line with one end short-circuited to the ground and the other end open-circuited. The metal line and the ground plane form a quasi transmission line. It is easy to derive that as the total length of this quasi 
transmission line equals a quarter of wavelength, the input reactance vanishes due to the resonance of the inductor-like short-circuited line and the capacitor-like open-circuited line. The corresponding return loss simulated by the commercial EM simulator IE3D [21] is plotted in the Fig. 2. Here, the length of the horizontal metal line is designed as a quarter wavelength of the fundamental frequency $2.45 \mathrm{GHz}$, so that a deep resonance occurs at that frequency with return loss larger than $20 \mathrm{~dB}$. It is noticed that another resonance presents at the frequency around $7.35 \mathrm{GHz}$, which is the triple of the fundamental frequency. The spiraled PIFA of Fig. 1 was simulated on FR4 substrate with thickness $0.8 \mathrm{~mm}$. The ground size of the substrate is set as $\mathrm{W} \times \mathrm{H}=46 \mathrm{~mm} \times 55 \mathrm{~mm}$. The antenna occupies an area of $l \times h=10.5 \mathrm{~mm} \times 6 \mathrm{~mm}$, which is only $50 \%$ of that of the PIFA without spiraling. The others parameters are $l_{s}=4.5 \mathrm{~mm}$, $w_{s}=3.5 \mathrm{~mm}$ and $g=2.0 \mathrm{~mm}$ and both the width and gap of spiral $=0.5 \mathrm{~mm}$.

\section{RESULTS AND DISCUSSION}

\subsection{Return Loss}

The proposed PIFA antenna if found to be resonant at three different frequencies namely $2.65 \mathrm{GHz}, 4.10 \mathrm{GHz}$ and $5.85 \mathrm{GHz}$ with the return loss of $-22 \mathrm{~dB},-15 \mathrm{~dB}$ and $-35 \mathrm{~dB}$ respectively. The corresponding BW's are $110 \mathrm{MHz}, 60 \mathrm{MHz}$ and $45 \mathrm{MHz}$ respectively.

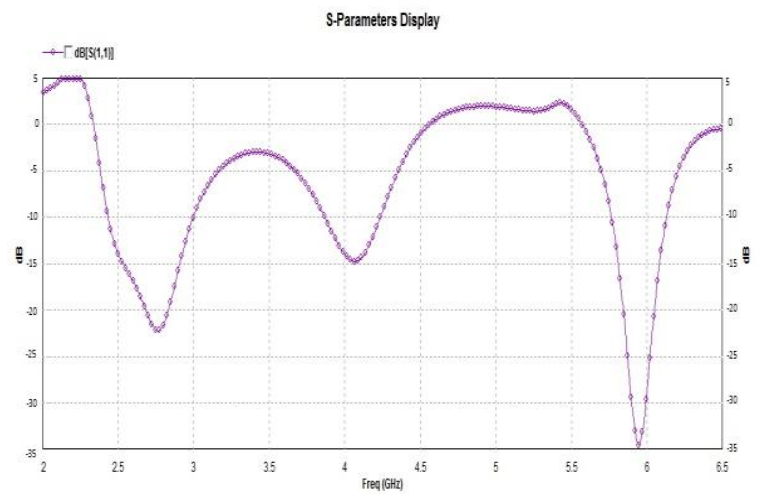

Fig2: Return Loss of Antenna

\subsection{Antenna Efficiency}

The Efficiency of antenna is around $92 \%$ at the resonant frequencies

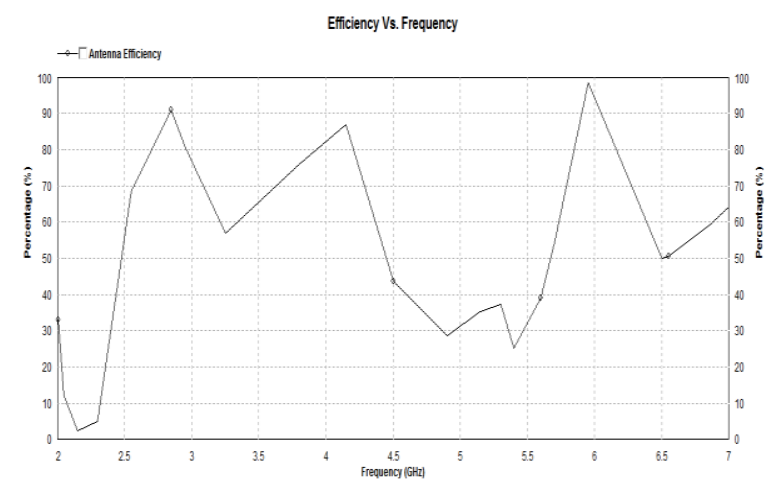

Fig3: Antenna Efficiency

\subsection{Gain}

The field gain of the antenna for lower to upper frequency ranges from -12.5 to $7.5 \mathrm{dBi}$ as shown in figure4.

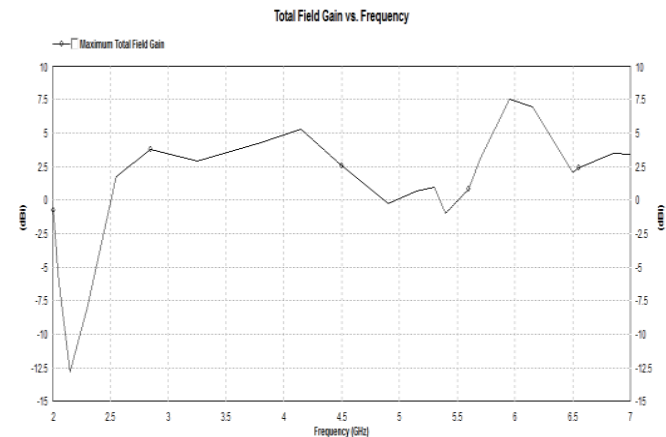

Fig4: Gain

\subsection{Antenna Radiation Pattern}

The E-field patterns of antenna at $2.65 \mathrm{GHz}, 4.10 \mathrm{GHz}$ and $5.85 \mathrm{GHz}$ are as shown the figure5, 6 and 7 respectively.

\section{$\prec t=2.55(\mathrm{GHz})$, t-total, phl=0 (deg)}
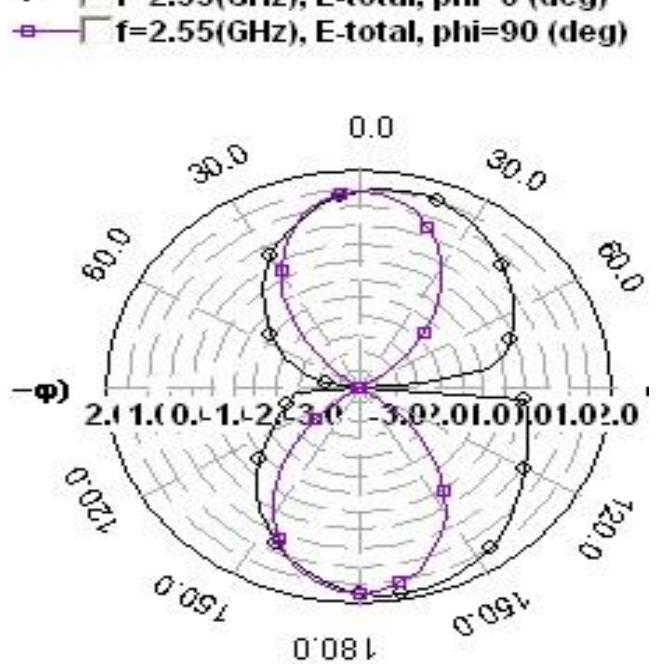

Fig5: At 2.55GHz

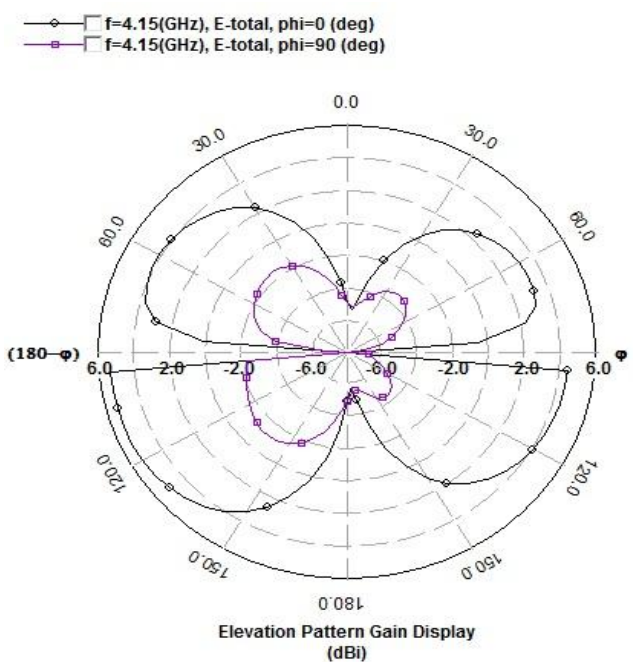

Fig 6: At 4.1 GHz 

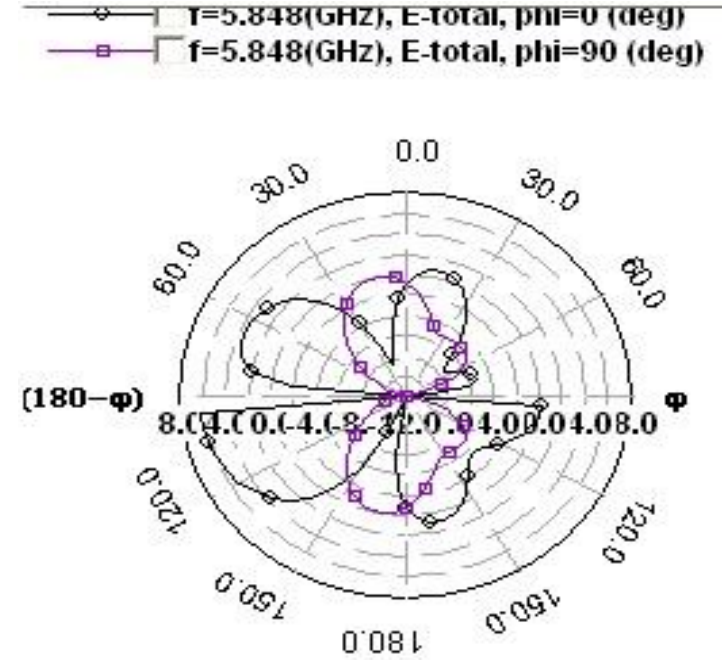

Fig. 7: At 5.85GHZ

\section{Azimuth Patterns}
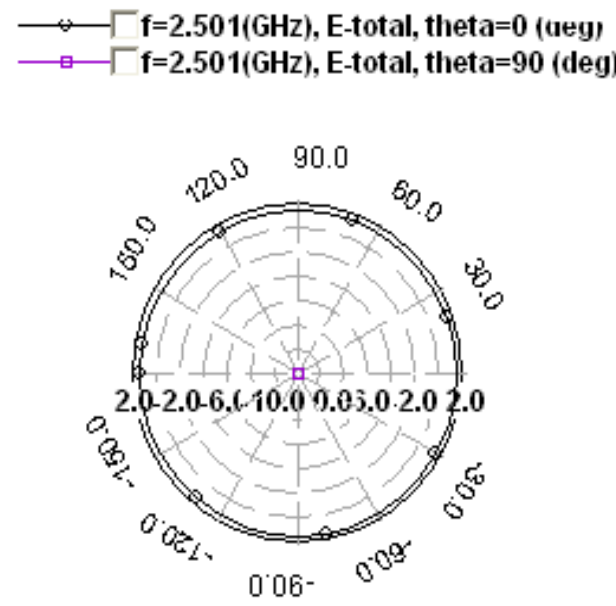

Fig 8: At 2.5GHz
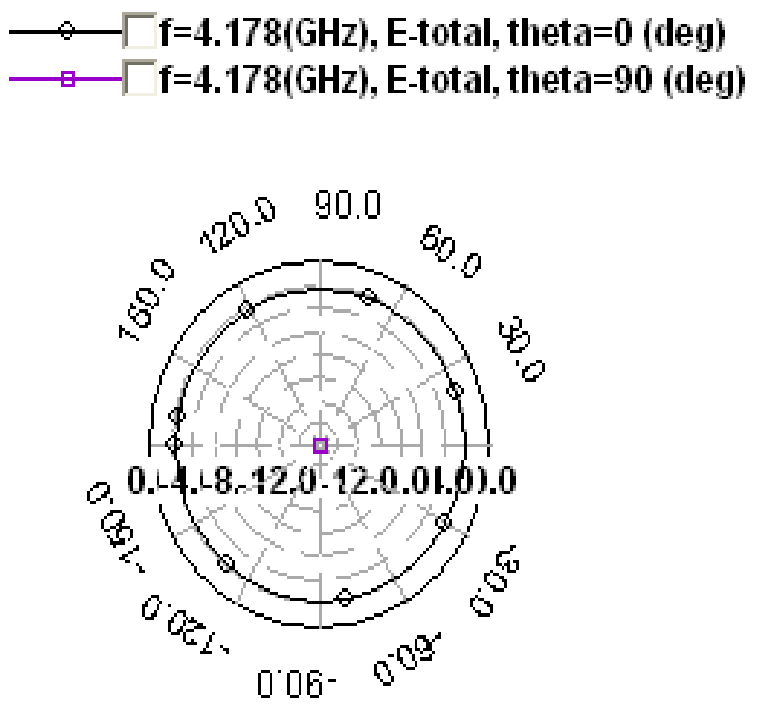

Fig 9: at 4.17GHz
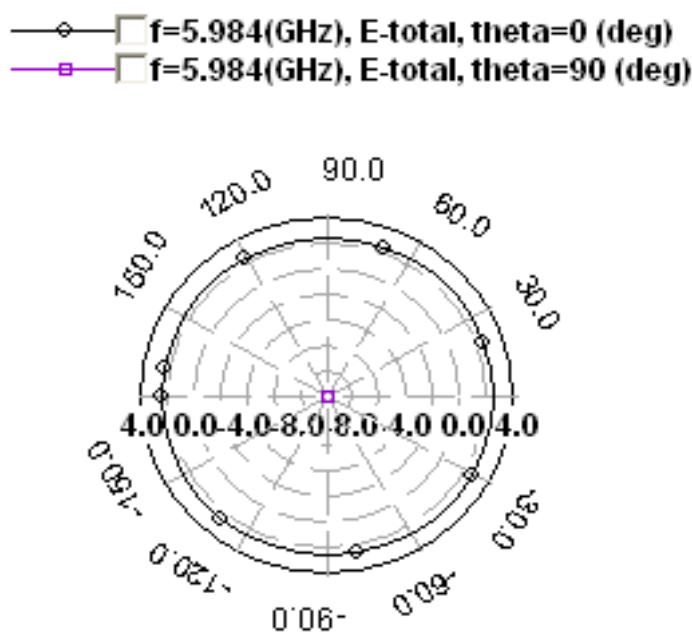

Fig 10: At 5.85 GHz

The Azimuth patterns of antenna at $2.65 \mathrm{GHz}, 4.10 \mathrm{GHz}$ and $5.85 \mathrm{GHz}$ are as shown the figure 8,9 and 10respectively. The pattern found to be omnidirectional.

\subsection{Directivity Of Antenna}

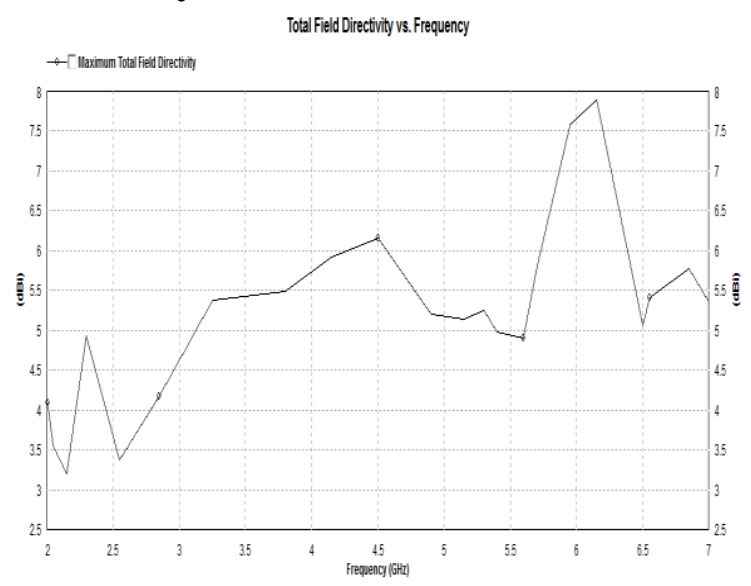

Fig11: Total Directivity Vs Frequency of Antenna

The field gain of the antenna for lower and upper frequency ranges from $5.5 \mathrm{dBi}$ to $7.9 \mathrm{dBi}$ as shown in figure 11 .

\subsection{D Pattern of PIFA Antenna}

3D Pattern of Spiraled PIFA Antenna at operating frequency of is obtained for Multiband.

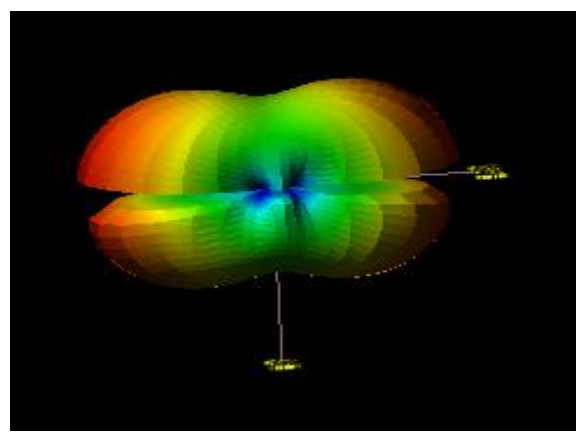

Fig 12: 3D View of Proposed Antenna 


\section{CONCLUSION}

In this paper, Spiraled PIFA -related Multiband antennas with spiralled and coupled structures have been designed and simulated using IE3D Software The simulated result shows the return loss of $-22 \mathrm{~dB},-15 \mathrm{~dB}$ and $-35 \mathrm{~dB}$ at $2.65 \mathrm{GHz}, 4.10 \mathrm{GHz}$ and $5.85 \mathrm{GHz}$ respectively. The field gain of $2.65 \mathrm{GH}$ the antenna for lower to upper frequency ranges from -12.5 to $7.5 \mathrm{dBi}$. The Efficiency of antenna is around $92 \%$ at the resonant frequencies. Thus the proposed antenna is much suitable for WLAN applications to cover all signal frequencies (from 5.1 to $5.85 \mathrm{GHz}$ ) of the IEEE $802.11 \mathrm{a} / \mathrm{b} / \mathrm{g}$ wireless band.

\section{REFERENCES}

[1] C. Wu, "Printed Antenna Structure for Wireless Data communications," U.S. 6008 774, 1999.

[2] C. Soras, M. Karaboikis, G. Tsachtsiris, and V. Makios, "Analysis and design of an inverted-F antenna printed on a PCMCIA card for the $2.4 \mathrm{GHz}$ ISM band," IEEE Antennas Propag. Mag., vol. 44, pp. 37-44, Feb. 2002.

[3] V. Stoiljkovic and G.Wilson, "A small planar inverted-F antenna with parasitic element for WLAN applications," in Proc. 10th Int. Conf. on Antennas and Propagation, Apr. 1997, vol. 1, pp. 82-85.

[4] T. Tiehong and Z. Zheng, "Applications of planar invertedF antenna for bluetooth," in Proc. Int. Conf. Communication Technology (ICCT 2003), Apr. 2003, vol. 2, pp. 1230-1233.

[5] Y. L. Kuo, Y. T. Cheng, and K. L.Wong, "Printed inverted$\mathrm{F}$ antennas for applications in wireless communication," in Proc. IEEE AP-S Int.Symp., Jun. 2002, vol. 3, pp. 454-457.

[6] H. Y. D. Yang, "Miniaturized Multiband printed antennas for wireless communications," in Proc. IEEE AP-S Int. Symp., Jul. 2005, vol. 1A, pp. 450-453.
[7] K..L.Wong, 'Planar Antennas for Wireless Communications"2001.

[8] C.A Balanis "Antenna Theory - Analysis and Design", Third Edition 2003.

\section{AUTHOR'S PROFILE}

T.Shanmuganantham was born May 12, 1974. He received B.E. degree in Electronics and Communication Engineering from University of Madras in 1996, M.E. degree in Communication Systems from Madurai Kamaraj University in 2000 and Ph.D. degree (Gold Medal) in the area of Antennas from National Institute of Technology, Tiruchirappalli, India under the guidance of Dr.S.Raghavan. He has 15 years of teaching experience in various reputed Engineering colleges such as SSN College of Engineering, Chennai, National Institute of Technology and Science, Chennai, PKIET, Karaikal. He has been with the Department of Electronics Engineering, School of Engineering \& Technology, Pondicherry University, Pondicherry as an Assistant Professor since 2010. His research interest includes Antennas, Microwave \& Millimeter-wave Engineering, Microwave Integrated Circuits, MEMS/NEMS, Meta Materials, Computational Electromagnetics, EMI/EMC, RF MEMS, RFIC Design, Optical Communication, Soft Computing for RF \& Microwave Engineering, Terahertz Technology. He has published 40 research papers in various national and International level Journals and Conferences. He is a member in IEEE, Life Member in IETE, Institution of Engineers, CSI, Society of EMC, ISTE, ISSS, OSI, ISI and ILA.

G.Rajender received his M.Tech. degree in Electronics from Department of Electronics Engineering, Pondicherry University, Pondicherry in the year 2012. His area of interest includes Antennas, Microwave Engineering. 